\title{
Dem Nachfolger zum Erfolg verhelfen
}

Richard O. Binswanger

\footnotetext{
Aus stilistischen Gründen wird die männliche Form verwendet. Frauen sind ausdrücklich mitgemeint.
}

Korrespondenz:

Dr. med. Richard O. Binswanger Radiologie und Nuklearmedizin FMH

Führungsschule Bodensee Münsterlingen

Oberer Seeweg 9

CH-8597 Landschlacht

r.binswanger@bluewin.ch

www.fsb-spital.ch
Sie leiten seit Jahren erfolgreich eine Abteilung oder Klinik und gehen dem Ende Ihrer Amtszeit entgegen. Sie spüren, dass Ihre Mannschaft nervös wird, ist sie doch unmittelbar betroffen. Fragen werden gestellt oder stehen unausgesprochen im Raum: Wer soll Nachfolger* werden? Wird auch der Richtige gewählt? Stellt er ganz neue Ansprüche? Können wir ihnen genügen? Was geschieht mit unseren Werten und der Betriebskultur? Bekomme ich beim Neuen eine Chance oder werde ich kaltgestellt? Muss ich eine andere Stelle suchen?

\section{Das Team vorbereiten}

Dazu sind sie verpflichtet, dem Team, Ihrer Institution und ganz besonders Ihrem Nachfolger gegenüber. Zuletzt tun Sie es auch für sich selbst. Legen Sie dar, dass eine einschneidende Veränderung bevorsteht: Ihr Nachfolger wird andere Ziele haben und andere Prioritäten setzen als Sie. Seine Persönlichkeit und seine Führung werden ganz anders sein als die Ihre. Ihre Mitarbeiter sollen sich darauf einstellen und vorbereiten. Sie werden eine neue Loyalität entwickeln müssen. Wer das nicht kann, soll die Zeit nutzen, sich noch besser für einen Stellenwechsel zu qualifizieren und zu positionieren.

\section{Die Wahl}

Halten Sie sich heraus. Alle Gründe sprechen dafür. Nehmen Sie der Institution die Verantwortung nicht ab. Wenn Sie mitbestimmen, sind Sie mitverantwortlich, auch beim allfälligen Scheitern Ihres Nachfolgers. Er soll die Wahl aus eigener Kraft schaffen. Ersparen Sie ihm den Makel, die Stelle nur dank Ihrer Mithilfe errungen zu haben. Allerdings: Wo es um den Erhalt erfolgversprechender Strukturen geht, sollen sie kämpfen. Und es gibt noch eine Ausnahme, aber das ist die einzige: Unfähige Wahlgremien müssen unterstützt werden (ist dann die Stelle noch erstrebenswert?).

\section{Die Einführung}

Halten Sie die Übergabezeit so kurz wie möglich, alle werden froh darüber sein. Übergeben Sie nur geordnete Akten, nichts Überflüssiges. Berichten Sie über Stärken und Schwächen. Schenken Sie Ihrem Nach-

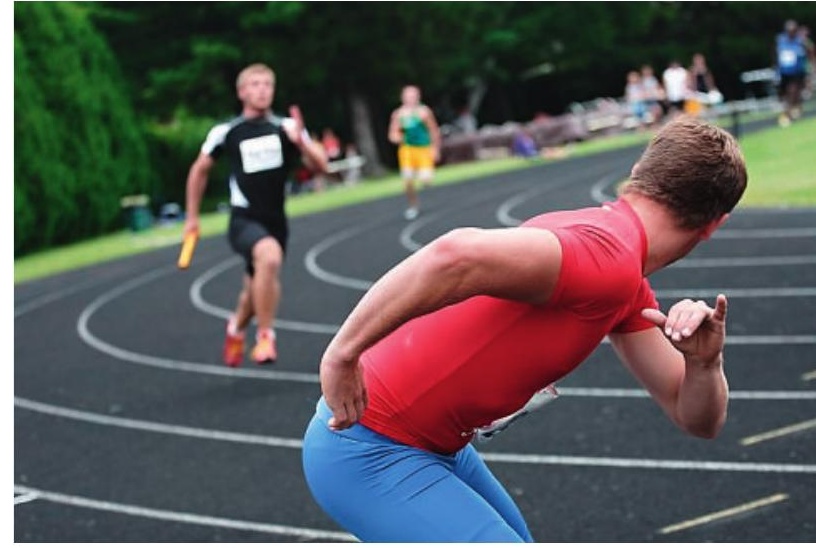

Mitentscheidend für den Erfolg des Nächsten: eine gute Übergabe.

folger reinen Wein ein. Selbstkritik hat viel für sich, wenn Sie dazu nicht fähig sind, merkt er es ja doch.

\section{Nach der Übergabe}

Jetzt sind Sie draussen, Sie gehören nicht mehr dazu. Das tut weh, sehr weh. Erkundigen Sie sich nirgends, wie es geht. Wenn es schlecht geht, wird es Ihnen sowieso zugetragen. Gönnen Sie Ihrem Nachfolger, was Sie einst selbst in Anspruch nahmen: Unsicherheit in der ersten Zeit. Fehler und Krisenerfahrungen machen. Daraus lernen. Bestärken Sie Ihre ehemaligen Mitarbeiter nicht in deren Kritik. Im Gegenteil: Erinnern Sie sie an ihre Dienst- und Loyalitätspflicht gegenüber dem Neuen.

\section{Helfen}

Es kann sein, dass Ihr Nachfolger Hilfe braucht und von Ihnen in Anspruch nehmen will. Helfen Sie, wo immer Sie können, zum Beispiel durch Mitarbeit bei Personalengpässen, wie sie aktuell immer häufiger vorkommen. (Im Kantonsspital Münsterlingen arbeiten derzeit vier ehemalige Chefärzte und leitende Ärzte in ihrer früheren Klinik weiter - ein Kulturwandel!). Und ganz wichtig: Beachten Sie dann Ihre eigene, neue Loyalitätspflicht. Helfen Sie Ihrem Nachfolger zum Erfolg. 